\section{Occurrence and molecular characterization of metallo- $\beta$-lactamases (MBLs) among Acinetobacter baumannii isolates from cancer patients}

\section{Abstract}

Background:During the last decade, the prevalence of carbapenemresistant infection associated with multidrug resistant (MDR) Acinetobacter baumanniiin patients has been continuously increasing. This prospective study aimed to determine the occurrence and molecular characterization of metallo- $\beta$-lactamases (MBLs) and carbapenem hydrolyzing oxacillinases among $A$. baumannii isolates from cancer patients over a period of 6 -month.

Methods:Antimicrobial susceptibility profile of 70 randomly collected A. baumannii isolates was first determined using disc diffusion test, and second, the MICs of 45 representative multidrug resistant (MDR) isolates were tested to most clinically used drugs in treatment of their infections using E-test. PCR assays were used to detect the common four types of class $D$ carbapenem hydrolyzing oxacillinases, two types of class A carbapenemases, four types of class B metallo- $\beta$-lactamases, and prevalence of Class 1 Integron among MDR isolates.

Results:All 70 isolates were MDR, including 100\% resistance to meropenem, aztreonam, piperacillin/tazobactum and $99 \%$ to carbapenem. All isolates carried blaOXA-23 and blaOXA-51, but none carried a blaOXA-24 like or blaOXA-58. The isolates were also positive for NDM-1, VIM, GES, KPC and SPM at the rates of $29 \%, 20 \%, 29 \%$, $19 \%, 7 \%$ and $2 \%$, respectively. Class 1 Integron was positive in $82 \%$ of $A$. baumannii isolates.

The clonal relationship of 42 MDR A. baumannii isolates using ERICPCR and constructed dendrogram showed 3 major genotype clusters
Husam F. qouzah', Feras Hawari², Luay F. Abu-Qatouseh ${ }^{3}$, Asem A. Shehabi ${ }^{1}$

1 Department of Pathology-Microbiology, School of Medicine, The Jordan University, Amman, Jordan

2 King Husain Cancer Center (KHCC), Amman, Jordan

3 Faculty of Pharmacy, Department of Biomedical Sciences, University of Petra, Amman, Jordan.

Contact information:

Asem A. Shehabi.

Address:Department of PathologyMicrobiology, School of Medicine, The Jordan University, Queen Rania str. 100, Amman, Jordan.

Đ ashehabi@ju.edu.jo 
of genetically related isolates. These include 4 genotype groups, each composed of 2 isolates with $100 \%$ similarity of DNA bands.

Conclusion:This study demonstrates that $A$. baumannii colonize frequently cancer patients in association with antibiotic treatment. The organism is mostly carrying wide spectrum of antibiotic resistance genetic factors, especially many types of ESBLs and MBLs and Class 1 Integron. This fact should be considered when therapy is selected for treatment of patients infected with MDR A. baumannii.

\section{Keywords}

Acinetobacter baumannii, ESBLs, MBLs, Class 1 Integron, Jordanian cancer patients.

\section{Introduction}

In recent years worldwide including Jordan, most clinical $A$. baumannii isolates have developed resistant to most clinically used drugs, and caused increased morbidity and mortality among hospitalized patients in intensive care units (ICUs) [1-4].

Acinetobacter spp. develop multidrug resistance through mechanism of mutation in penicillin-binding proteins (PBPs), alterations in outer membrane proteins (OMPs) and increased activity of efflux pumps [5]. However, resistance to $\beta$ - lactams appears to be primarily caused by production of $\beta$ - lactamases which include extended-spectrum$\beta$-lactamases (ESBLs), oxacillinases, and metallo- $\beta$ lactamases [6].

A. baumannii acts first often as colonizer rather than a pathogen because of its wide distribution and colonizing capability [1, 7], especially in immune-compromised and among patients with prolonged hospital stay [8]. The spectrum of infections caused by this pathogen include ventilator-associated pneumonia (VAP) which is developed after prolonged hospitalization or mechanical ventilation and prior use of antibiotics [4, 9-10].
Many factors contribute to the ability of $A$. baumannii to cause infections in hospitalized patients. First, $A$. baumannii has the capacity to survive for long periods in various body parts of patients and their environment. Secondly, the genomic makeup of this organism allows it to acquire resistance to many antibiotics within a short period [11]. However, the rates of antibiotic resistance vary from region to region and among hospitals [12]. Almost all studies indicate that MDR $A$. baumannii infections are difficult to treat, spread quickly among hospitalized patients and can be associated with high mortality due to blood sepsis or ventilator associated pneumonia [2, 4, 12-14].

This study describes the occurrence and the mechanism of antibiotic resistance of $A$. baumannii isolated from cancer patients.

\section{Patients and Methods}

\section{Collection of A. baumannii isolates}

This prospective study included a total of $70 \mathrm{~A}$. baumannii isolates, were recovered from clinical specimens of patients who were investigated for 
presence of $A$. baumannii during hospitalization or investigation as outpatients at a Cancer Center in Amman, Jordan, over a period of 6-months (2016) as shown in the Table 2. Approval was obtained from the Institution Ethical Review Board (IERB) at the King Hussein Cancer Center (KHCC), Amman, Jordan, for conducting and publishing this study.

\section{Identification of $A$. baumannii isolates}

All isolateswere first identified using BioMerieux VITEK 2 Automated Microbiology System (France). Later all collected isolates were sub-cultured on Blood and MacConkey agar plates and incubated at $37^{\circ} \mathrm{C}$ for $24 \mathrm{hr}$. Pure growth was again confirmed as $A$. baumannii according to the following characteristics; negative oxidase test, negative lactose and glucose fermentation in Kligler iron tubes, and later by presence of OXA-51 gene using PCR. Five fresh colonies were inoculated in brain-heart infusion agar plus $15 \%$ glycerol and kept frozen at $-70{ }^{\circ} \mathrm{C}$ until used for further investigation.

\section{Antibiotic susceptibility tests}

The susceptibility of $A$. baumannii isolates to antibiotics was determined using the disc diffusion method according to the guidelines of CLSI 2016 [15]. The minimum inhibitory concentrations (MICs) of isolates were determined by the E-test (ABBioMérieux, France) for imipenem, amikacin and colistin. Interpretations of the MICs in the E-test were done according to the guidelines of CLSI 2016 [15].

\section{Genomic DNA Extraction from $A$. baumannii Isolates}

Genomic DNA was extracted according to the manufacturer's instructions of Wizard Genomic DNA purification kit (Promega, USA).

\section{Plasmid DNA extraction from $A$. baumannii isolates}

The bacterial plasmid was extracted using the EZ-10 Spin Column Plasmid DNA Minipreps Bio Basic kit (Canada) according to manufactures protocol.

\section{Detection of genes encoding blaOXA} carbapenemases, metalo-beta-lactamases, and class-1 integron in A. baumannii using PCR

All primer target genes of blaOXA carbapenemases, metalo-beta-Lactamases, their sequences, product sizes, annealing temperatures were used according to references as shown in Table 1. $\beta$-lactamases genes (OXA-58, OXA-51, OXA-24, OXA-23 [16], IMP2, VIM-2, SPM, NDM, [17], GES [18], NDM-1(19)KPC [20] and class-1integron [21].

The following control strains were used in the experiment, which were kindly donated by Prof. Monzer Hamza, Laboratoire Microbiologie Sante et Environnement (LMSE), Ecole Doctorale des Sciences et de Technologie, Faculte de Sante Publique, Universite Libanaise, Tripoli, Lebanon):A. baumannii (OXA-51 positive), A. baumannii (OXA-23 positive), A. baumannii (IMP-2 positive), K. pneumonia (blaKPC positive; ATCC BAA-1705), K. pneumonia (blaNDM-1positive; ATCC BAA-2146), and P. aeruginosa (ATCC 2 7853) was used in susceptibility test.

PCR tests were carried out in $25 \mu$ reaction with $2.5 \mu \mathrm{l}$ of extracted DNA, $20 \mathrm{pmol}$ of each primer (Alpha DNA, Montreal, Canada), $12.5 \mu$ GoTaq $^{\circledR}$ Green master mix (Promega, USA). The volume was made up to $25 \mu \mathrm{l}$ using nuclease free water. DNA concentrations of each sample was evaluated using Nanodrop 2000c (Thermo scientific, USA). The PCR amplification assays for the target genes were performed using programmable PCR-Thermocycler (Bioerxp cycler, China). Control tubes containing master mix without template DNA were included in each run as negative control. Tubes were held at $4^{\circ} \mathrm{C}$ when the cycles were ended. The amplified products and the PCR DNA marker were separated via electrophoresis on $2 \%$ agarose gels containing $15 \%$ Red safe ${ }^{\mathrm{TM}}$ stain $(5 \mu \mathrm{l})$, for $40-50 \mathrm{~min}$ at 120 volts, and then visualized using Gel documentation system including:UV camera, monitor and printer (UVP, USA). 
Table 1. Primers of blaOXA - carbapenemases, Metalo-beta-Lactamases ,Class-1 integrons, ERIC.

\begin{tabular}{|c|c|c|c|c|}
\hline Gene targets & Primer Sequence $\left(5^{\prime} \rightarrow 3^{\prime}\right)$ & Annealing Temp.oC & Product size (bp) & Reference \\
\hline bla OXA-51 & $\begin{array}{l}\mathrm{F} \rightarrow \text { TAATGCTTTGATCGGCCTTG } \\
\mathrm{R} \rightarrow \text { TGGATTGCACTTCATCTTGG }\end{array}$ & 60 & 353 & \multirow{4}{*}{16} \\
\hline bla OXA-23 & $\begin{array}{c}\mathrm{F} \rightarrow \text { GATCGGATTGGAGAACCAGA } \\
\mathrm{R} \rightarrow \text { ATTTCTGACCGCATT TCCAT }\end{array}$ & 57 & 501 & \\
\hline bla OXA-24 & $\begin{array}{l}\mathrm{F} \rightarrow \mathrm{GGTTAGTTGGCCCCCTTAAA} \\
\mathrm{R} \rightarrow \text { AGTTGAGCGAAAAGGGGATT }\end{array}$ & 57 & 246 & \\
\hline bla OXA-58- & $\begin{array}{l}\mathrm{F} \rightarrow \text { AAGTATTGGGGCTTGTGCTG } \\
\mathrm{R} \rightarrow \mathrm{CCCCTCTGCGCTCTACATAC}\end{array}$ & 57 & 599 & \\
\hline IMP & $\begin{array}{c}\mathrm{F} \rightarrow \mathrm{GGA} \text { ATA GAG TGG CTT AAY TCTC } \\
\mathrm{R} \rightarrow \mathrm{GGT} \text { TTA AYA AAA CAA CCA CC }\end{array}$ & 52 & 232 & \multirow{4}{*}{17} \\
\hline VIM & $\begin{array}{c}\mathrm{F} \rightarrow \mathrm{GAT} \text { GGT GTT TGG TCG CAT A } \\
\mathrm{R} \rightarrow \mathrm{CGA} \text { ATG CGC AGC ACC AG }\end{array}$ & 52 & 390 & \\
\hline SPM & $\begin{array}{c}\mathrm{F} \rightarrow \mathrm{AAA} \text { ATC TGG GTA CGC AAA CG } \\
\mathrm{R} \rightarrow 5^{\prime}-\text { ACA TTA TCC GCT GGA ACA GG }\end{array}$ & 52 & 271 & \\
\hline NDM & $\begin{array}{l}\mathrm{F} \rightarrow \mathrm{GGT} \text { TTG GCG ATC TGG TTT TC } \\
\mathrm{R} \rightarrow \mathrm{CGG} \text { AAT GGC TCA TCA CGATC }\end{array}$ & 52 & 621 & \\
\hline GES & $\begin{array}{l}\mathrm{F} \rightarrow \text { ATG CGC TTC ATT CAC GCA C } \\
\mathrm{R} \rightarrow \text { CTA TTT GTC CGT GCT CAG GA }\end{array}$ & 56 & 863 & 18 \\
\hline$N D M-1$ & $\begin{array}{c}\mathrm{F} \rightarrow \text { ATT AGC CGC TGC ATT GAT } \\
\mathrm{R} \rightarrow \text { CAT GTC GAG ATA GGA AGT G }\end{array}$ & 58 & 154 & 19 \\
\hline$K P C$ & $\begin{array}{l}\text { F- GATACCACGTTCCGTCTGG } \\
\text { R- GCAGGTTCCGGTTTTGTCTC }\end{array}$ & 52 & 246 & 20 \\
\hline $\begin{array}{l}\text { intl1 } \\
\text { intl1 }\end{array}$ & $\begin{array}{c}\mathrm{F} \rightarrow \text { ACATGTGATGGCGACGCACGA } \\
\mathrm{R} \rightarrow \text { ATTTCTGTCCTGGCTGGCGA }\end{array}$ & 55 & 600 & 21 \\
\hline $\begin{array}{l}E R / C-1 \\
E R / C-2\end{array}$ & $\begin{array}{l}\text { ATGTAAGCTCCTGGGGATTCACAAG } \\
\text { TAAGTGACTGGGGTGAGCG }\end{array}$ & 52 & Multiple Bands & 22 \\
\hline
\end{tabular}

\section{Enterobacterial repetitive consensus (ERIC)-PCR}

This test was performed in $50 \mu \mathrm{l}$ volumes containing $10 \mathrm{ng}$ of genomic DNA from $A$. baumannii clinical isolates, $4 \mathrm{mM} \mathrm{MgCl2}, 50 \mathrm{pM}$ each of primer ERIC-1 and 2 as described by Jeong et al. [22].

\section{Statistical analysis}

Statistical analysis was done using SPSS version 20, chi square test and t-test were used to analyzed categorical variablesand to measure the significance of the association between the study variables. If less than 5 a fisher exact test was used. P-value of $\leq 0.05$ was considered significant $\backslash$.

\section{Results}

Table 2 Shows the sources of $70 \mathrm{~A}$. baumannii isolates within the period of study (March 2016 to October 2016). The majority of samples were collected from nasal swabs (30\%) and perianal swabs (21\%). Table 3 shows the demographic characteristics of cancer patients with positive $A$. baumannii isolates. The majority of patients (56\%) were over 50 years old and were in-patient (90\%) rather than out-patient (10\%). Most of the patients (68\%) have received medication prior to collection their specimens. The results of antimicrobial susceptibility using disc diffusion method are presented in Table $4 \mathrm{~A}$. baumannii isolates were $100 \%$ resistant 
Table 2. Sources, number and percent of collected samples from patients.

\begin{tabular}{l|c|c|}
\multicolumn{1}{c|}{ Source } & \multicolumn{2}{c|}{ Samples* } \\
\hline Nasal swab NS) & No & $\%$ \\
\hline Perianal swab PS) & 21 & 30 \\
\hline TRAP & 15 & 21 \\
\hline Wound swab WS) & 8 & 11 \\
\hline Blood & 8 & 11 \\
\hline Urine & 4 & 6 \\
\hline High vaginal Swab HVS) & 5 & 7 \\
\hline Sputum & 3 & 4 \\
\hline Broncho alveolar lavage BAL) & 2 & 3 \\
\hline Throat & 2 & 3 \\
\hline Pleural fluid & 1 & 1.5 \\
\hline Pleural fluid & 1 & 1.5 \\
\hline \multicolumn{1}{|c|}{ *: Only one sample was included from each patient. } \\
\hline
\end{tabular}

to meropenem, piperacillin/tazobactum, aztreonam and ceftazidime, 99\% resistant to imipenem, and ciprofloxacin, 76\%, 77\% resistant to amikacin and gentamycin, respectively. The results of MICs for the three commonly used drugs amikacin, colisitn and imipenem against $A$. baumannii isolates are shown in Table 4.

A total of 45 A. baumannii isolates were $100 \%$ positive to OXA23 like and OXA51, and all of these were negative to OXA58 like and OXA24 genes. Table 5 shows the distribution of other potential genes of VIM, GES, NDM-1, NDM, IMPa, KPC, and SPM werefound in 64\%, 42\%, 29, 20\%, 7\%, 7\%, $2 \%$, respectively, while integron-1 was presented in $83 \%$ of the isolates.

The genetic relationship of 42 MDR A. baumannii isolates from hospitalized patients as shown in the dendrogram indicated 3 major genotype clusters of genetically related isolates (Figure 1). These include

Table 3. Demographic characteristics of 70 cancer patients with positive A. baumannii isolates.

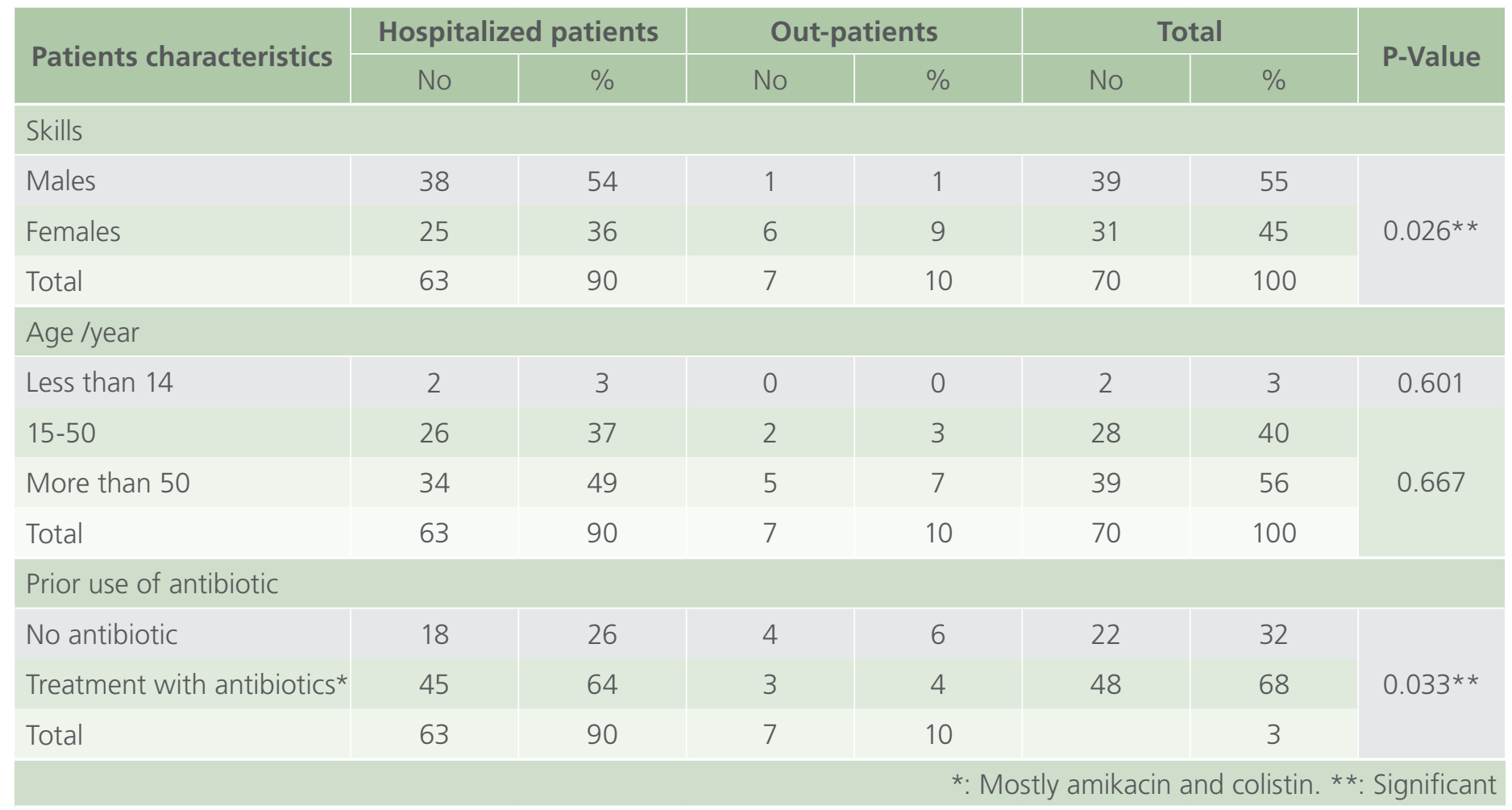


Table 4. Antimicrobial resistance patterns of $70 \mathrm{~A}$. baumannii isolates using disc diffusion and E-tests for MICs.

\begin{tabular}{|c|c|c|c|c|c|c|c|c|}
\hline \multirow{3}{*}{$\begin{array}{l}\text { Antimicrobial } \\
\text { agent }\end{array}$} & \multirow{2}{*}{\multicolumn{2}{|c|}{$\begin{array}{l}\text { resistant } \\
\text { isolates }\end{array}$}} & \multirow{3}{*}{$\begin{array}{c}\mathrm{MIC}_{50} \\
\mathrm{mg} / \mathrm{L}\end{array}$} & \multirow{3}{*}{$\begin{array}{c}\mathrm{MIC}_{90} \\
\mathrm{mg} / \mathrm{L}\end{array}$} & \multirow{3}{*}{$\begin{array}{c}\text { MIC- } \\
\text { range } \\
\text { mg/L }\end{array}$} & \multirow{2}{*}{ Gene name } & \multicolumn{2}{|c|}{ Positive isolates } \\
\hline & & & & & & & \multirow{2}{*}{$\begin{array}{l}\text { No } \\
45\end{array}$} & \multirow{2}{*}{$\begin{array}{c}\% \\
100\end{array}$} \\
\hline & No & $\%$ & & & & OXA-23 & & \\
\hline $\begin{array}{l}\text { Meropenem } \\
\text { (Mem) }\end{array}$ & 70 & 100 & - & - & - & OXA-24 & \multicolumn{2}{|c|}{0} \\
\hline aztreonam (Atm) & 70 & 100 & - & - & - & OXA-51 & 45 & 100 \\
\hline \multirow{2}{*}{$\begin{array}{l}\text { Piperacillin/ } \\
\text { Tazobactum (Ptz) }\end{array}$} & \multirow[b]{2}{*}{70} & \multirow[b]{2}{*}{100} & \multirow[b]{2}{*}{-} & \multirow[b]{2}{*}{-} & \multirow[b]{2}{*}{ - } & OXA-58 & \multicolumn{2}{|c|}{0} \\
\hline & & & & & & VIM & 29 & 64 \\
\hline Ceftazidime (Caz) & 70 & 100 & - & - & - & GES & 19 & 42 \\
\hline \multirow{2}{*}{$\begin{array}{l}\text { Ciprofloxacin } \\
\text { (Cip) }\end{array}$} & \multirow{2}{*}{69} & \multirow{2}{*}{99} & \multirow[b]{2}{*}{ - } & \multirow{2}{*}{ - } & \multirow{2}{*}{ - } & NDM-1 & 13 & 29 \\
\hline & & & & & & NDM & 9 & 20 \\
\hline Imipenem (IMI) & 69 & 99 & 15.6 & 28.5 & $0.38-32$ & IMP & 3 & 7 \\
\hline Gentamicin (GM) & 54 & 77 & - & - & - & KPC & 3 & 7 \\
\hline Amikacin (Ak) & 53 & 76 & 98.3 & 177 & $1-256$ & SPM & 1 & 2 \\
\hline Colistin & & & 0.26 & 0.47 & $0.019-2$ & Integron-1 & 37 & 82 \\
\hline
\end{tabular}

Figure 1: Dendrogram of the $42 \mathrm{~A}$. baumannii isolates from hospitalized patients.

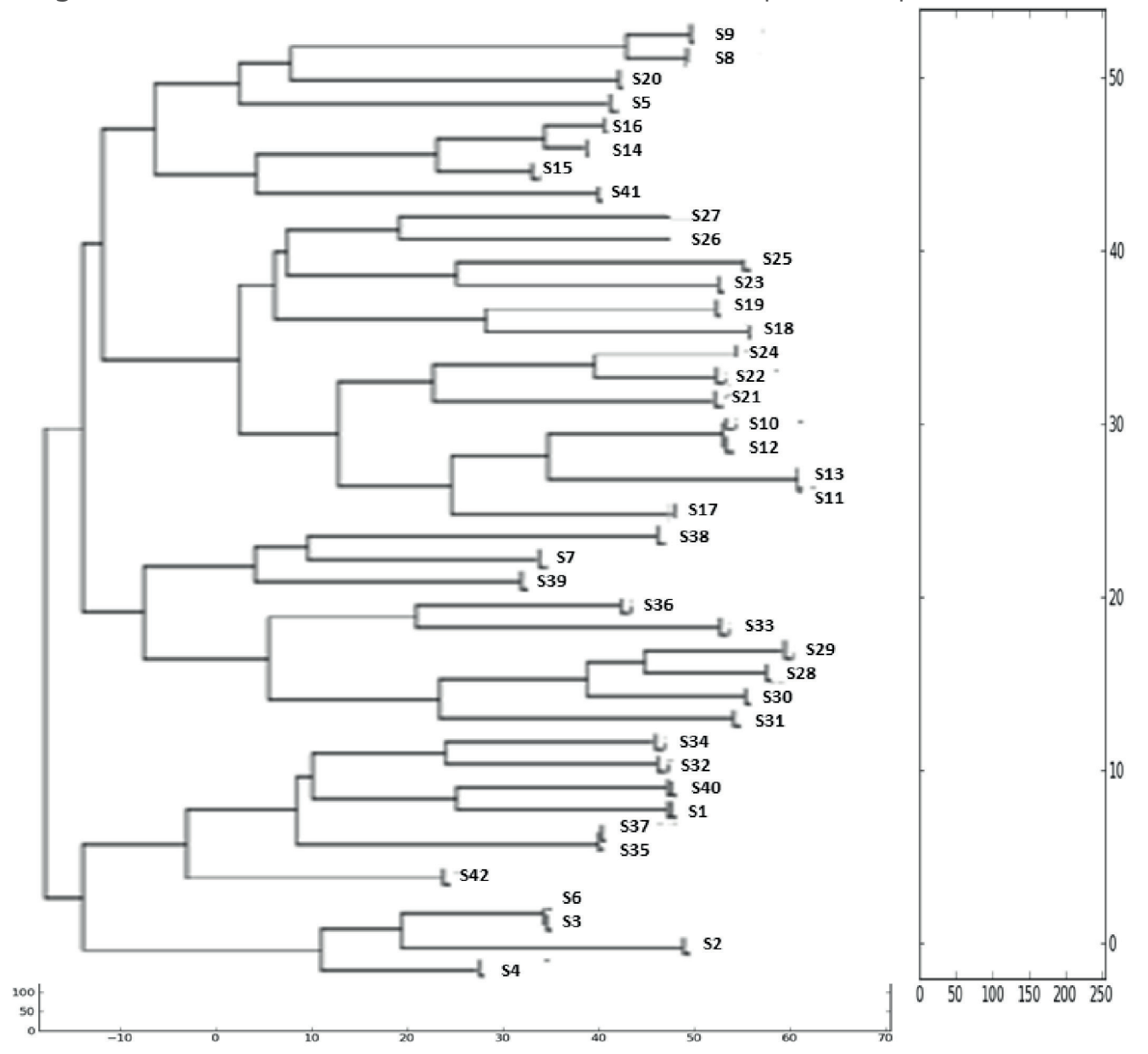


4 genotype groups, each composed of 2 isolates with $100 \%$ similarity of DNA bands.

The identity of class-1 integron PCR products of $5 \mathrm{~A}$. baumannii isolates were confirmed by sending them to Macrogen Inc. (Seoul, Korea) for sequencing and the results were analyzed using alignment search tool of Blast. (http://www.ncbi.nlm.nih.gov/ BLAST) and the multiple sequence alignment program, CLUSTALW (http://www.ebi.ac.uk/clustalw).

\section{Discussion}

This study has demonstrates that many body sites of cancer patients are frequently colonized with $A$. baumannii, especially their nares andperianal site. Invasive blood infection was detected among few percentage (6\%)of hospitalized cancer patients during the 6-month study period (Table 2).The rest of the isolates can be considered colonizers and might become potential pathogens for patients under certain condition, especially in association with the use of invasive procedures [23-24]. There is no significance difference in general demographic characteristics between male and female patients or their ages, whereas treatment with antibiotics showed increased significantly the chance of $(P=0.033)$ coIonization with $A$. baumanni. Additionally, hospitalized patients were at increased risk for colonization with $A B(90 \% ; P=0.026)$ when compared to outpatients (10\%) with A. baumannii (Table 3). Recent studies from Jordan and other countries reported that A. Baumannii frequently colonizes hospitalized patients, causing sporadic invasive infection and nosocomial outbreaks, especially among critically ill patients and in ICUs [2, 25-27].

This study demonstrates that the majority of $A$. baumannii species isolates were resistant in the range between $76 \%$ to $100 \%$ to commonly useful antimicrobial agents in the treatment of gram-negative infections, including infections due to $A$. baumannii (Table 4). Previous studies which has been performed over the last few years at the Jordan
University Hospital and KHCC in Amman, have also found that the majority of $A$. baumannii isolates from patients and hospital environment sources was also multidrug resistant $[2,3,28]$.

The ability to acquire resistance to a broad range of antimicrobial agents within a short period and during treatment is commonly observed in A. baumannii $[4,29]$. High mortality rates among critically ill patients infected with MDRor extensively drugresistant (XDR) A. baumannii strains (resistant to all antibiotics except colistin and tigecycline, have been recently described in many regions [30-32].

This study shows extremely high rate of carbapenems-resistance (99-100\%) among A. baumannii isolates. The prevalence of imipenem-resistance among $A$. baumannii isolates was $99 \%$. This rate is very high compared to resistance rates of clinical isolates reported few years ago from Jordan and neighboring countries which ranged between $90 \%$ to $64 \%[3,31,32,33]$. A previous Jordanian study has also indicated that majority of Abaumannii isolates from environmental and clinical sources was multidrug resistant, except for colistin and tigecycline similar to the case in other countries such as Lebanon [3, 32].

Carbapenems are frequently used as the drugs of choice in treatment of infections caused by MDR Gram-negative bacteria including $A$. baumannii. Increased resistance to carbapenems in $A$. baumannii has raised special concerns during the last decade, especially since it is associated mostly with the production of acquired carbapenemases belonging to either carbapenem-hydrolyzing OXA-type class D - $\beta$-lactamases or class B metallo- $\beta$-lactamases [32, 35-36]. The results of this study demonstrate that all representative examined 45 MDR $A$. baumannii isolates were $100 \%$ positive for genes of blaOXA-51, and blaOXA-23, but none of the isolates was positive to OXA-24 or OXA-58. A recent Jordanian study carried at the Jordan University Hospital also showed that all examined $A$. baumannii isolates harbored a blaOXA-51gene, 58\% has a blaOXA- 
23gene, and $38.8 \%$ has a blaOXA-24 gene [3]. It is well known that blaOXA-51 gene, is an enzyme that naturally exists in $A$. baumannii and has very weak carbapenem hydrolyzing activity [37].While the presence of plasmid-borne blaOXA-23 and blaOXA-58 genes have been shown to contribute significantly to carbapenem resistance in $A$. baumannii worldwide [38]. However, the distribution of carbapenem-hydrolyzing oxacillinases varies among regions and hospitals [3, 32-35, 38]. A study used multivariate analysis demonstrated that the risk factors for acquisition of MDR A. baumannii were not related specifically to presence of cancer, but rather due to exposure of patients to health care procedures, especially dialysis, antibiotic treatment and length of stay in intensive care unities $[4,7]$.

The present study also demonstrates that all $A$. baumannii isolates were susceptible to colistin. This result is similar to most recent studies from neighboring countries which has reported high susceptibility rates of clinical $A$. baumannii isolates to colistin [2$3,25,32,35]$. However, with an increase of using colistin to treat carbapenem-resistant $A$. baumannii infections, colistin resistance could be later emerged [39].

This study revealed that 37 of the 45 (82\%) MDR A. baumannii isolates harbored class-1 Integrons (Table 5). Previous studies from Jordan has demonstrated that class 1- integrons is frequently found in clinical and environmental isolates of Gram-negative bacteria such as $A$. baumannii and $E$. coli and are often associated with their MDR strains $[28,40]$. The presence of the integrase gene in the majority of our A. baumannii clinical isolates in association with other resistance markers provided a strong evidence that these isolates have the potential for acquisition more antimicrobial resistance genes in future. It has been often observed that MDR A. baumannii strains involved in hospital outbreaks have carried class 1 integrons [41-42].

The ERIC-PCR analysis as shown by dendrogram demonstrated that few $A$. baumannii isolates might have been circulated among cancer patients (Figure 1). Further testing of these isolates using multilocus sequence typing (MLST) or DNA sequencing could confirm this result.

In conclusion, the results of this study demonstrate that body colonization with $A$. baumannii increased in association with antibiotic treatment of cancer patients. The majority of $A$. baumannii are carrying a wide spectrum of genetic resistance factors, especially many important types of blaOXAcarbapnemases which will limit using valuable drugs in treatment of $A$. baumannii invasive infection.

\section{Acknowledgement}

This work was supported by grant from The University of Jordan, Dean of Research (No. 22/20162017). We thank the KHCC for providing the clinical isolates of $A$. baumannii in this study.

\section{Conflicts of interest}

There is no conflict of interests

\section{References}

1. Wong D, Nielsen TB, Bonomo RA, Pantapalangkoor P, Luna B, et al. Clinical and pathophysiological overview of Acinetobacter infections:a century of challenges. Clin Microbiol Rev 2017; 30:409-447.

2. Nazer L, Karabsheh A,Rimawi D, Hawari F. Characteristics and Outcomes of Acinetobacter baumannii Infections in Critically III Patients with Cancer:A Matched Case-Control Study. Microb Drug Resist2015; 21(5):556-561

3. Obeidat N, Jawdat F, Al-Bakr GA , Shehabi AA. Major biological characteristics of Acinetobacter baumannii isolates form hospital environmental and patients' respiratory tract sources. American J Infect Control 2014; 42:401-404.

4. AntunesL, ViscaP, Towner KJ. Acinetobacterbaumannii:evolution of a globalpathogen. Pathog Dis 2014; 71:292-301.

5. Cerqueira GM, Peleg AY. Insights into Acinetobacter baumannii pathogenicity. IUBMB Life2011; 63:1055-1060.

6. Noori M, Karimi A, Fallah F, Hashemi A, Alimehr S,et al. High Prevalence of Metallo-beta-lactamase Producing Acinetobacter baumannii Isolated From Two Hospitals of Tehran, Iran, Arch Pediatr Infect Dis. 2014; 2(3). 
7. Garc'ia-Garmendia J-L, Ortiz-Leyba C, Garnacho-Montero J, Jiménez-Jiménez F-J, Pérez-Paredes $C$, et al. Risk factors for Acinetobacter baumannii nosocomial bacteremia in critically ill patients:a cohort study. Clin Infect Dis 2001; 33:939-946.

8. Montefour K, Frieden J, Hurst S, Helmich C, Headley D, et al. Acinetobacter baumannii:an emerging multidrug-resistant pathogen in critical care. Crit Care Nurse 2008; 28:15-25.

9. Routsi C, Pratikaki M, Platsouka E, Sotiropoulou C, Nanas S, et al. Carbapenem-resistant versus carbapenem-susceptible Acinetobacter baumannii bacteremia in a Greek intensive care unit:risk factors, clinical features and outcomes. Infection 2010; 38:173-180.

10. Luna CM, Aruj PK. Nosocomial Acinetobacter pneumonia. Respirology 2007; 12:787-791.

11. Lei Gao, Yuan Lyu, Yun Li. Trends in Drug Resistance of Acinetobacter baumannii over a 10-year Period:Nationwide Data from the China Surveillance of Antimicrobial Resistance Program. Chin Med J (Engl). 2017; 20; 130(6):659-664.

12. Hurley JC. World-wide variation in incidence of Acinetobacter associated ventilatorassociated pneumonia:a meta-regression. BMC Infect Dis 2016; 16:577

13. Chang $\mathrm{K}-\mathrm{C}$, Lin $\mathrm{M}-\mathrm{F}$, Lin N-T, Wu W-J, Kuoet H-Y, al. Clonal spread of multidrug-resistant Acinetobacter baumannii in eastern Taiwan. J Microbiollmmunol Infect 2012; 45:37-42.

14. Lee C-R, Lee JH, Park M, Park KS, Bae IK, et al. Biology of Acinetobacter baumannii:Pathogenesis, antibiotic resistance mechanisms, and prospective treatment options. Front. Cell Infect Microbiol 2017; 7:1-8.

15. Clinical Laboratory and Standards Institute (CLSI). Methods for dilution antimicrobial susceptibility tests for bacteria that grow aerobically; approved standard - tenth edition. CLSI document M07-A10 Villanova, PA, USA:CLSI, 2016.

16. Woodford N, Ellington MJ, Coelho JM, Turton JF, Ward $M E$, et al. Multiplex PCR for genes encoding prevalent OXA carbapenemases in Acinetobacter spp. Int J Antimicrob Agents 2006; 27(4):351-3.

17. Poirel L, Walsh TR, Cuvillier V, Nordmann P. Multiplex PCR for detection of acquired carbapenemase genes. Diagn Microbiol Infect Dis 2011; 70(1):119-23.

18. Cicek AC, Saral A, Iraz M, Ceylan A, Duzgun AO, et al. OXAand GES-type beta-lactamases predominate in extensively drugresistant Acinetobacter baumannii isolates from a Turkish UniversityHospital. Eur J Clin Microbiol Infect Dis 2014; 20(5):410-5.

19. Naas T, Ergani A, Carrer A, Nordmann P. Real-time PCR for detection of NDM-1 carbapenemase genes from spiked stool samples. AntimicrobAgents Chemother 2011; 55(9):4038-43.

20. Hindiyeh M, Smollen G, Grossman Z, Ram D, Davidson Y, et al. Rapid detection of blaKPCcarbapenemase genes by real-time PCR. J ClinMicrobiol 2008; 46(9):2879-83.
21. PloyMC, DenisF, CourvalinP, LamberT. MolecularCharacterization of Integrons in Acinetobacter baumannii:Description of a Hybrid Class 2 Integron. Antimicrob Agents Chemother 2000; 44(10):2684-2688.

22. Jeong $S H$, IL KB , Seung GS, Kwang OP, Young J AN, et al. First Detection of blalMP-1 in Clinical Isolate Multiresistant Acinetobacter baumannii from Korea. J. Microbiol. Biotechnol 2006; 16(9):1377-1383.

23. Helal S, El Anany M, Ghaith D, RabeeaS. The Role of MDRAcinetobacter baumannii in Orthopedic Surgical Site Infections. Surg Infect (Larchmt)2015; 16:518-522.

24. Al-Hassan L, El Mehallawy H, Amyes SGB. Diversity in Acinetobacter baumannii isolates from paediatric cancer patients in Egypt. ClinMicrobiol Infect2013; 19:1082-1088.

25. Ghaith DM, Zafer MM, Al-Agamy MH, Alyamani EJ, Booq $R Y$, et al. The emergence of a novel sequence type of MDR Acinetobacter baumannii from the intensive care unit of an Egyptian tertiary care hospital. Ann Clin Microbiol Antimicrob 2017; 16:34

26. Gecgel KS, Demircan N. Antibiotic resistance rates among bacterial isolatesfrom infected patients of intensive care unit over the period (2011-2016) in Bursa, Turkey. IAJAA 2017; Vol. 7 No. 2:4

27. Anudit C, Kooltheat N, Potup P, Sranujit RP, Usuwanthim K. Nosocomial infection of multidrug-resistant Acinetobacter baumannii in Thailand. Am J Infect Control 2016; 44:1161-1163.

28. Al-Dabaibah N, Obeidat NM, Shehabi AA. Epidemiology features of Acinetobacter baumannii colonizing respiratory tracts of ICU patients. IAJAA 2012; 2:1, 1-7.

29. Peleg AY, de Breij A, Adams MD, Cerqueira GM, Mocali S, et al. The success of Acinetobacter species; genetic, metabolic and virulence attributes. PLoS One 2012; 7:e46984.

30. Spellberg B, Bonomo RA. Combination Therapy for Extreme Drug Resistant (XDR)Acinetobacterbaumannii:Ready for PrimeTime? Crit Care Med 2015; 43:1332.

31. Doi Y, Murray GL, Peleg AY . Acinetobacter baumannii:evolution of antimicrobial resistance-treatment options. SeminRespirCrit. Care Med 2015; 85-98.

32. Dahdouh E, Hajjar M, Suarez M, Daoud Z . Acinetobacter baumannii Isolated from Lebanese Patients:Phenotypes and Genotypes of Resistance, Clonality, and Determinants of Pathogenicity. Front. Cell. Infect. Microbiol. 2015; 6:

33. Alyamani EJ, Khiyami MA, Booq RY, Alnafjan BM, Altammami $M A$, et al.. Molecular characterization of extended-spectrum beta-lactamases (ESBLs)produced by clinical isolates of Acinetobacter baumannii in Saudi Arabia. Ann Clin Microbiol Antimicrob 2015; 14:38.

34. Cicek AC, Saral A, Iraz M, Ceylan A, Duzgun AO, et al. . OXA and GES-type $\beta$-lactamases predominate in extensively drugresistant Acinetobacter baumannii isolates from a Turkish University Hospital. Clin Microbiol Infect 2014; 20:410-415. 
35. Mathlouthi N, Al-Bayssari C, Bakour S, Rolain JM, Chouchani C. Prevalence and emergence of carbapenemases-producing Gram-negative bacteria in Mediterranean basin. Crit Rev Microbiol. 2017 Feb; 43(1):43-61.

36. Touati M, Diene SM, Racherache A, Dekhil M, Djahoudi A, et al. Emergence of blaOXA-23 and blaOXA-58 carbapenemaseencoding genes in multidrug-resistant Acinetobacter baumannii isolates from University Hospital of Annaba, Algeria. Int J Antimicrob Agents 2012; 40:89-91.

37. Zarrilli R, Pournaras S, Giannouli M, Tsakris A . Global evolution of multidrug resistant Acinetobacter baumannii clonal lineages. Int J Antimicrob Agents 2013; 41:11-19.

38. Mostachio AK, Levin AS, Rizek C, Rossi F, Zerbini J, et al. . High prevalence of OXA-143 and alteration of outer membrane proteins in carbapenem-resistant Acinetobacter spp. isolates in Brazil. Int J Antimicrob Agents 2012; 39:396-401.

39. Qureshi AZ,Hittle EL, O'Hara AJ, Rivera IJ, Syed A, et al. ColistinResistant Acinetobacter baumannii:Beyond Carbapenem Resistance. Clin Infect Dis 2015; 60(9):1295-303.

40. Shehabi AA, Odeh JF, Fayyad M . Characterization of antimicrobial resistance andclass 1 integrons found in Escherichia coli isolates from human stools and drinking water sources in Jordan. J Chemother 2006; 18:468-472.

41. Sung JY, Koo SH, Kim S, Kwon KC . Epidemiological characterizations of class 1 integrons from multidrug-resistant Acinetobacter isolates in Daejeon, Korea. Ann Lab Med 2014; 34:293-299.

42. Lin M-F, Lan C-Y. Antimicrobial resistance in Acinetobacter baumannii: From bench to bedside. World J Clin Cases 2014; $2: 787$.

\section{Publish in The International}

Arabic Journal of Antimicrobial Agents

The Journal is an open access peer-reviewed journal that publishes scientific papers about all aspects of antimicrobials. The journal will publish original research articles, reviews, brief reports and case reports dealing with basic and clinical antibacterial agents, antiviral, antiprotozoals, antituberculuous, antifungal and antihelminthes agents. All manuscripts must be prepared in English, and are subject to a rigorous and fair peer-review process. Accepted papers will immediately appear online. The journal aims to advance the knowledge, attitude and the research of chemotherapy in the Arabic world in cooperation with international, national scientific and public societies as well as research centers with similar aims and objectives. 